\title{
Pyrrolizine-5-carboxamides: Exploring the impact of various substituents on anti-inflammatory and anticancer activities
}

\author{
AHMED M. GOUDA ${ }^{1,2 *}$ \\ AHMED H. ABDELAZEEM ${ }^{2}$ \\ ASHRAF N. ABDALLA ${ }^{3,4}$ \\ MUHAMMAD AHMED ${ }^{3}$ \\ ${ }^{1}$ Department of Pharmaceutical \\ Chemistry, Faculty of Pharmacy \\ Umm Al-Qura University, Makkah \\ 21955, Saudi Arabia \\ ${ }^{2}$ Department of Medicinal \\ Chemistry, Faculty of Pharmacy \\ Beni-Suef University, Beni-Suef \\ 62514, Egypt \\ ${ }^{3}$ Department of Pharmacology and \\ Toxicology, Faculty of Pharmacy \\ Umm Al-Qura University, Makkah \\ 21955, Saudi Arabia
}

${ }^{4}$ Department of Pharmacology Medicinal and Aromatic Plants Research Institute

National Center for Research Khartoum 2404, Sudan

Accepted March 18, 2018

Published online April 11, 2018
Towards optimization of the pyrrolizine-5-carboxamide scaffold, a novel series of six derivatives (4a-c and $\mathbf{5 a - c}$ ) was prepared and evaluated for their anti-inflammatory, analgesic and anticancer activities. The (EZ)-7-cyano-6-((4-hydroxybenzylidene)amino)$N$-( $p$-tolyl)-2,3-dihydro-1H-pyrrolizine-5-carboxamide (4b) and (EZ)-6-((4-chlorobenzylidene)-amino)-7-cyano- $N$-( $p$-tolyl)2,3-dihydro- $1 H$-pyrrolizine-5-carboxamide $(5 \mathbf{b})$ bearing the electron donating methyl group showed the highest anti-inflammatory activity while (EZ)-6-((4-chlorobenzylidene)amino)7-cyano- $N$-phenyl-2,3-dihydro- $1 H$-pyrrolizine-5-carboxamide (5a) was the most active analgesic agent. Cytotoxicity of the new compounds was evaluated against the MCF-7, A2780 and HT29 cancer cell lines using the MTT assay. Compounds $\mathbf{4 b}$ and $\mathbf{5 b}$ displayed high anticancer activity with $I C_{50}$ in the range of 0.30 $0.92 \mu \mathrm{mol} \mathrm{L}{ }^{-1}$ against the three cell lines, while compound (EZ)$N$-(4-chlorophenyl)-7-cyano-6-((4-hyd roxybenzylidene)amino)-2,3-dihydro-1H-pyrrolizine-5-carboxamide (4c) was the most active against MCF-7 cells $\left(I_{50}=0.08 \mu \mathrm{mol} \mathrm{L}^{-1}\right)$. Both the anti-inflammatory and anticancer activities of the new compounds were dependent on the type of substituent on the phenyl rings. Substituents with opposite electronic effects on the two phenyl rings are preferable for high cytotoxicity against the MCF-7 and A2780 cells. COX inhibition was suggested as the molecular mechanism of the anti-inflammatory activity of the new compounds while no clear relationship could be observed between COX inhibition and anticancer activity. Compound 5b, the most active against the three cell lines, induced dose-dependent early apoptosis with $0.1-0.2 \%$ necrosis in MCF-7 cells. New compounds showed promising drug-likeness scores while the docking study revealed high binding affinity to COX-2. Taken together, this study highlighted the significant impact of the substituents on the anti-inflammatory and anticancer activity of pyrrolizine-5-carboxamides, which could help in further optimization to discover good leads for the treatment of cancer and inflammation.

Keywords: pyrrolizine-5-carboxamide, anticancer, anti-inflammatory, COXs, apoptosis, substituent electronic effect

\footnotetext{
*Correspondence; e-mail address: amsaid@uqu.edu.sa; ahmed.gouda@pharm.bsu.edu.eg
} 
Cancer and inflammation are closely linked biological processes where many antiinflammatory agents displaying anticancer activity have provided evidence for this tight correlation (1-4). The use of NSAIDs in prevention and treatment of cancer has been discussed in several reports. NSAIDs can restore normal apoptosis and inhibit angiogenesis in cancer cells (2). Moreover, the COX-2 enzyme plays an important role in cellular proliferation and apoptosis (4). The upregulation of COX-2 in benign and malignant cancers provided evidence for this role (5). In addition, several COX-2 inhibitors displayed potent anticancer activity mediated by the induction of apoptosis $(6,7)$.

Recently, several reports have focused on the anti-inflammatory and anticancer activities of the pyrrolizine derivatives (8-10). Licofelone (Fig. 1) is one of the derivatives that underwent a phase III clinical trial as an anti-inflammatory drug (11). Licofelone also displayed potent anticancer activity with an $I C_{50}$ value of $5.5 \mu \mathrm{mol} \mathrm{L}-1$ against the human breast MCF-7 cell line (12). Although licofelone acts as a dual COX/5-LOX inhibitor, Tavolari et al. $(13,14)$ have provided evidence that it induces apoptosis through the mitochondrial pathway instead of COX/5-LOX inhibition.

MR22388 is another pyrrolizine derivative that showed potent antiproliferative activity against the leukemia L1210 cell line with the $I C_{50}$ value of $15 \mathrm{nmol} \mathrm{L}^{-1}$ (Fig. 1). The anticancer activity of MR22388 was mediated by the induction of apoptosis, inhibition of tubulin polymerization and inhibition of several kinases (15-17). Moreover, we have reported several pyrrolizine-5-carboxamide derivatives with potent anticancer activity against the MCF-7 and A549 cancer cell lines $(9,18)$. Anticancer activities of these pyrrolizines were associated with activation of caspase 3/7 enzymes, inhibition of COXs and induction of apoptosis $(9,18)$.

In this study, scaffold A was designed by bearing two phenyl rings (A and B) attached to the pyrrolizine nucleus via two atom spacers (Fig. 1). To evaluate the impact of electronic effects of the substituents on the two phenyl rings on the anti-inflammatory, anal-

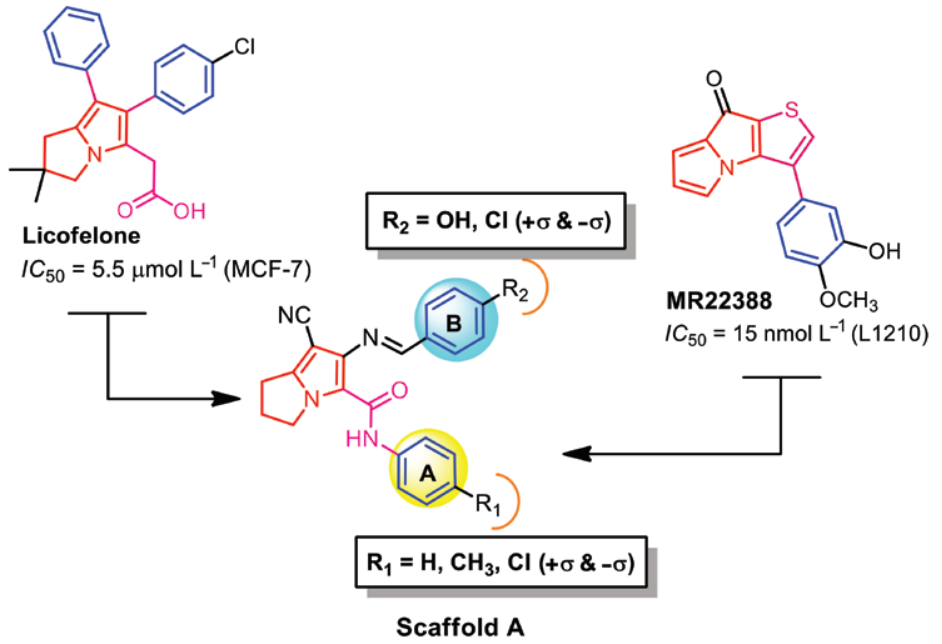

Fig. 1. Pyrrolizine-based anticancer agents and rational design of scaffold A. 
gesic and anticancer activities of the new pyrrolizines, different types of substituents, including electron-donating groups $\left(\mathrm{CH}_{3}\right.$ and $\left.\mathrm{OH}\right)$ and electron-withdrawing group $(\mathrm{Cl})$, were used in the new compounds.

\section{EXPERIMENTAL}

\section{Chemicals and instruments}

All the chemical reagents and solvents used were purchased from Sigma-Aldrich (USA). Solvents were dried according to the literature when necessary. Purity of the new compounds was checked with TLC. Melting points are uncorrected and were determined with an IA 9100MK-Digital melting point apparatus (Cole-Parmer, USA). Infrared spectra (IR) were recorded using a BRUKER TENSOR 37 spectrophotometer (Bruker, USA) from $\mathrm{KBr}$ discs. The proton magnetic spectra were recorded on a BRUKER AVANCE III at 500 $\mathrm{MHz}$ (Bruker) in $\mathrm{CDCl}_{3}$ and $J$ constants were given in $\mathrm{Hz}$. The ${ }^{13} \mathrm{C}$ NMR and DEPT135 (distortionless enhancement by polarization transfer) spectra of the new compounds in $\mathrm{CDCl}_{3}$ were done on the BRUKER AVANCE III (Bruker) at $125 \mathrm{MHz}$. Mass spectra were recorded using GCMS on a Shimadzu Qp-2010 Plus mass spectrometer (Shimadzu, Japan) at $70 \mathrm{eV}(\mathrm{EI})$.

\section{Syntheses}

2-Pyrrolidin-2-ylidene-malononitrile (1). - Synthesis of 2-pyrrolidin-2-ylidene-malononitrile (1) was achieved according to previous reports (19). To a solution of 2-pyrrolidinone $(2.5 \mathrm{~g}, 29.4 \mathrm{mmol})$ in dry benzene $(30 \mathrm{~mL})$, dimethyl sulfate $\left(\mathrm{CH}_{3}\right)_{2} \mathrm{SO}_{4}(3.7 \mathrm{~g}, 29.4 \mathrm{mmol})$ was added under stirring. The reaction mixture was refluxed for 3 hours and then allowed to cool to room temperature. The solution was cooled in an ice-bath and rendered alkaline by dropwise addition of sodium hydroxide ( $\left.15 \mathrm{~mol} \mathrm{~L} \mathrm{~L}^{-1}, 1.5 \mathrm{~mL}\right)$. The temperature was kept below $5{ }^{\circ} \mathrm{C}$ during the addition of sodium hydroxide. The organic phase was separated, dried over anhydrous sodium sulfate and filtered. Malononitrile $(1.25 \mathrm{~g}, 19.1 \mathrm{mmol})$ was added to the benzene solution at room temperature. The produced solution was then stirred, whereby white crystals were formed on scratching the wall of the beaker. The crystals were collected, dried to give $5.2 \mathrm{~g}$ and recrystallized from aqueous ethanol.

2-Chloro-1N-[4-(un)substituted-phenyl)-acetamide (2a-c). - Synthesis of acetanilides 2a-c was achieved according to a previous report (20) with some modifications. The appropriate aniline $(27 \mathrm{mmol})$ was dissolved in a small amount of glacial acetic acid. Chloroacetyl chloride ( $4.55 \mathrm{~g}, 40.5 \mathrm{mmol}$ ) was added dropwise to the solution under continuous stirring and cooling. After addition of chloroacetyl chloride was completed, a saturated solution of sodium acetate $(1.5 \mathrm{~mL})$ was added dropwise under stirring. The solution was kept cool during the addition of chloroacetyl chloride by using an ice-cooled water-bath. The white precipitate formed was collected on a Büchner funnel, washed with water 2 times $(2 \times 30 \mathrm{~mL})$ and recrystallized from aqueous ethanol. The following compounds were prepared: 2-chloro- $N$-phenylacetamide (2a), 2-chloro- $N$ - $(p$-tolyl)acetamide (2b) and 2-chloro- $N$ - $(4$ chlorophenyl)acetamide (2c). 
Table I. Physicochemical data and mass spectra of new compounds $4 a-c$ and $5 a-c$

\begin{tabular}{|c|c|c|c|c|c|c|}
\hline \multirow[t]{2}{*}{ Compd. } & \multirow{2}{*}{$\begin{array}{c}\text { Yield } \\
(\%)\end{array}$} & \multirow{2}{*}{$\begin{array}{l}\text { M. p. } \\
\left({ }^{\circ} \mathrm{C}\right)\end{array}$} & \multirow{2}{*}{$\begin{array}{l}\text { Molecular } \\
\text { formula } \\
\quad\left(M_{\mathrm{r}}\right)\end{array}$} & \multicolumn{2}{|c|}{ Elemental analysis (\%) } & \multirow[t]{2}{*}{ MS (EI) } \\
\hline & & & & Calcd. & Found & \\
\hline $4 a$ & 68 & $276-278$ & $\begin{array}{c}\mathrm{C}_{22} \mathrm{H}_{18} \mathrm{~N}_{4} \mathrm{O}_{2} \\
(370.40)\end{array}$ & $\begin{array}{l}\text { C: } 71.34 \\
\text { H: } 4.90 \\
\text { N: } 15.13\end{array}$ & $\begin{array}{l}\text { C: } 71.17 \\
\text { H: } 5.39 \\
\text { N: } 15.32\end{array}$ & $\begin{array}{l}m / z(\%) 373\left(\mathrm{M}^{+}+3,22\right), 372\left(\mathrm{M}^{+}+2,\right. \\
5), 371\left(\mathrm{M}^{+}+1,20\right), 370\left(\mathrm{M}^{+}, 100\right), 369 \\
\left(\mathrm{M}^{+}-1,75\right), 298(11), 77(1)\end{array}$ \\
\hline $4 b$ & 63 & $279-281$ & $\begin{array}{c}\mathrm{C}_{23} \mathrm{H}_{20} \mathrm{~N}_{4} \mathrm{O}_{2} \\
(384.43)\end{array}$ & $\begin{array}{l}\text { C: } 71.86 \\
H: 5.24 \\
\text { N: } 14.57\end{array}$ & $\begin{array}{l}\text { C: } 71.80 \\
\text { H: } 4.83 \\
\text { N: } 14.96\end{array}$ & $\begin{array}{l}m / z(\%) 388\left(\mathrm{M}^{+}+4,3\right), 370(79), 280 \\
(2), 279(19), 278(100), 277(32), 266 \\
(40), 250(25), 174(18), 92(19), 77 \\
(17)\end{array}$ \\
\hline $4 c$ & 61 & $284-286$ & $\begin{array}{c}\mathrm{C}_{22} \mathrm{H}_{17} \mathrm{ClN}_{4} \mathrm{O}_{2} \\
(404.85)\end{array}$ & $\begin{array}{l}\text { C: } 65.27 \\
\text { H: } 4.23 \\
\text { N: } 13.84\end{array}$ & $\begin{array}{l}\text { C: } 64.82 \\
\text { H: } 4.58 \\
\text { N: } 14.01\end{array}$ & $\begin{array}{l}m / z(\%) 407\left(\mathrm{M}^{+}+3,2\right), 406\left(\mathrm{M}^{+}+2,8\right), \\
405\left(\mathrm{M}^{+}+1,7\right), 404\left(\mathrm{M}^{+}, 27\right), 403 \\
\left(\mathrm{M}^{+}-1,7\right), 370(100), 278(4)\end{array}$ \\
\hline $5 a$ & 58 & $227-229$ & $\begin{array}{c}\mathrm{C}_{22} \mathrm{H}_{17} \mathrm{ClN}_{4} \mathrm{O} \\
(388.85)\end{array}$ & $\begin{array}{l}\text { C: } 67.95 \\
\text { H: } 4.41 \\
\text { N: } 14.41\end{array}$ & $\begin{array}{l}\text { C: } 68.31 \\
\text { H: } 4.87 \\
\text { N: } 14.56\end{array}$ & $\begin{array}{l}m / z(\%) 391\left(\mathrm{M}^{+}+3,3\right), 390\left(\mathrm{M}^{+}+2,\right. \\
\text { 20), } 389\left(\mathrm{M}^{+}+1,25\right), 388\left(\mathrm{M}^{+}, 69\right), 370 \\
(5), 296(100), 277(11), 77(1)\end{array}$ \\
\hline $5 b$ & 62 & $236-237$ & $\begin{array}{c}\mathrm{C}_{23} \mathrm{H}_{19} \mathrm{Cl}- \\
\mathrm{N}_{4} \mathrm{O}(402.88)\end{array}$ & $\begin{array}{l}\text { C: } 68.57 \\
\text { H: } 4.75 \\
\text { N: } 13.91\end{array}$ & $\begin{array}{l}\text { C: } 68.94 \\
\text { H: } 5.14 \\
\text { N: } 14.09\end{array}$ & $\begin{array}{l}m / z(\%) 405\left(\mathrm{M}^{+}+3,3\right), 404\left(\mathrm{M}^{+}+2,9\right), \\
403\left(\mathrm{M}^{+}+1,7\right), 402\left(\mathrm{M}^{+}, 26\right), 401 \\
\left(\mathrm{M}^{+}-1,2\right),(370(9), 296(100), 268(3), \\
77(8)\end{array}$ \\
\hline $5 c$ & 63 & $239-241$ & $\begin{array}{c}\mathrm{C}_{22} \mathrm{H}_{16} \mathrm{Cl}_{2} \mathrm{~N}_{4} \mathrm{O} \\
(423.29)\end{array}$ & $\begin{array}{l}\text { C: } 62.42 \\
\text { H: } 3.81 \\
\text { N: } 13.24\end{array}$ & $\begin{array}{l}\text { C: } 62.31 \\
\text { H: } 3.84 \\
\text { N: } 13.28\end{array}$ & $\begin{array}{l}m / z(\%) 425\left(\mathrm{M}^{+}+3,8\right), 424\left(\mathrm{M}^{+}+2,\right. \\
\text { 20), } 423\left(\mathrm{M}^{+}+1,6\right), 422\left(\mathrm{M}^{+}, 28\right), 383 \\
(27), 372(37), 354(21), 339(16), 311 \\
\text { (22), } 296(100), 280(19), 155(2), 113 \\
\text { (3), } 77(2)\end{array}$ \\
\hline
\end{tabular}

6-Amino-7-cyano-N-[4-(un)substituted-phenyl]-2,3-dihydro-1H-pyrrolizine-5-carboxamide $(3 a-c)$. - Synthesis of pyrrolizine-5-carboxamides 3a-c was achieved according to a previous report (21). Appropriate acetanilides $2 \mathrm{a}-\mathrm{c}(7.5 \mathrm{mmol})$ were refluxed for $24 \mathrm{~h}$ with an equimolar ratio of 2-pyrrolidin-2-ylidene-malononitrile (1) in dry acetone in the presence of a catalytic amount of anhydrous potassium carbonate $(0.5 \mathrm{~g}, 3.75 \mathrm{mmol})$. The mixture was filtered while hot, the content of the flask was washed 2 times with acetone $(2 \times 15 \mathrm{~mL})$, left to cool and yellowish white crystals were separated. The following compounds were prepared: 6-amino-7-cyano- $N$-phenyl-2,3-dihydro- $1 H$-pyrrolizine5-carboxamide (3a), 6-amino-7-cyano- $N$-( $p$-tolyl)-2,3-dihydro-1H-pyrrolizine-5-carboxamide (3b) and 6-amino- $N$-(4-chlorophenyl)-7-cyano-2,3-dihydro-1H-pyrrolizine-5-carboxamide (3c).

(EZ)-7-cyano-6-((4-hydroxy/chlorobenzylidene)amino)-N-(un)substitutedphenyl-2,3-dihydro-1H-pyrrolizine-5-carboxamide $(4 a-c$ and $5 a-c)$. General procedures. - A mixture of the appropriate pyrrolizine-5-carboxamides $3 \mathrm{a}-\mathrm{c}(2 \mathrm{mmol})$ and appropriate aldehyde $(2.2 \mathrm{mmol})$ in absolute ethanol $(30 \mathrm{~mL})$ in the presence of glacial acetic acid $(0.5 \mathrm{ml})$ was refluxed for 6 hours. 
The reaction mixture was then concentrated and set aside to cool. The yellow crystals formed were collected and recrystallized from chloroform-acetone (1:1). The following compounds were prepared: (EZ)-7-cyano-6-((4-hydroxybenzylidene)amino)- $N$-phenyl-2,3-dihydro- $1 H$ pyrrolizine-5-carboxamide (4a), (EZ)-7-cyano-6-((4-hydroxybenzylidene)amino)- $N$-( $p$-tolyl)2,3-dihydro- $1 H$-pyrrolizine-5-carboxamide (4b), (EZ)-N-(4-chlorophenyl)-7-cyano-6-((4hydroxybenzylidene)-amino)-2,3-dihydro-1H-pyrrolizine-5-carboxamide (EZ)-6-((4-chlorobenzylidene)amino)-7-cyano- $N$-phenyl-2,3-dihydro-1H-pyrrolizine-5-carboxamide (5a), (EZ)-6-((4-chlorobenzylidene)-amino)-7-cyano- $N$-( $p$-tolyl)-2,3-dihydro- $1 H$ pyrrolizine-5-carboxamide (5b) and (EZ)-6-((4-chlorobenzylidene)amino)- $N$-(4-chlorophenyl)-7-cyano-2,3-dihydro-1H-pyrrolizine-5-carbox-amide (5c).

Physicochemical properties and spectral data of the synthesized compounds are presented in Tables I and II.

\section{Animals}

The anti-inflammatory testing of the new compounds $4 \mathbf{a}-\mathbf{c}$ and $\mathbf{5 a - c}$ was performed on adult albino rats (both sexes) weighing 100-140 g, while the analgesic activity was tested on albino mice of either sex (18-22 g). The animals were acquired from the animal house of King Abdul-Aziz University Medical Research Centre, Jeddah (Kingdom of Saudi Arabia). The animals were housed in polypropylene cages bedded with wooden husk. The animals were kept with food and tap water ad libitum and under a $12 \mathrm{~h} \mathrm{light/dark} \mathrm{cycle).}$

Animals were divided into 8 groups of six animals each. Rats were hydrated orally with $3 \mathrm{~mL}$ water. Animals were kept in the lab for one week before starting the tests so as to adapt to lab conditions.

The animal ethical clearance was obtained from the Ethical Committee of the College of Pharmacy, Umm Al-Qura University, Makkah, KSA.

\section{Pharmacological screening}

Anti-inflammatory activity. - Carrageenan induced rat paw edema method was used for the anti-inflammatory activity evaluation according to a previous report (22). The control group was given saline solution containing a few drops of carboxy methyl cellulose (CMC) (group I). Ibuprofen (100 mg kg-1, $0.48 \mathrm{mmol} \mathrm{kg}^{-1} \mathrm{bm}$ ) prepared in distilled water containing a few drops of CMC was given to group II. Tested compounds $4 a-c$ and $5 a-c ~(0.48$ $\mathrm{mmol} \mathrm{kg}{ }^{-1} \mathrm{bm}$ ) suspended in distilled water containing a few drops of CMC were given to groups III-VIII.

Experimental procedures were performed following our previous report (10). Induction of inflammation was performed by a subcutaneous (s.c.) injection of $50 \mu \mathrm{L}$ of $0.5 \%$ carrageenan-sodium gel (Sigma-Aldrich, USA) into the sub-plantar region of the right hind paw. The dorsoventral diameter (thickness) of the right and left hind paws of each rat was measured using digital calipers with $0.01 \mathrm{~mm}$ accuracy (Cole-Parmer, USA). Edema thickness was measured 2 and $3 \mathrm{~h}$ after induction of inflammation. Results are presented in Table III.

In vivo analgesic activity. - Analgesic activity of the new compounds $4 \mathbf{a}-\mathbf{c}$ and $5 \mathbf{a}-\mathbf{c}$ was evaluated using the hot-plate test according to a previous report (23). The standard drug, 


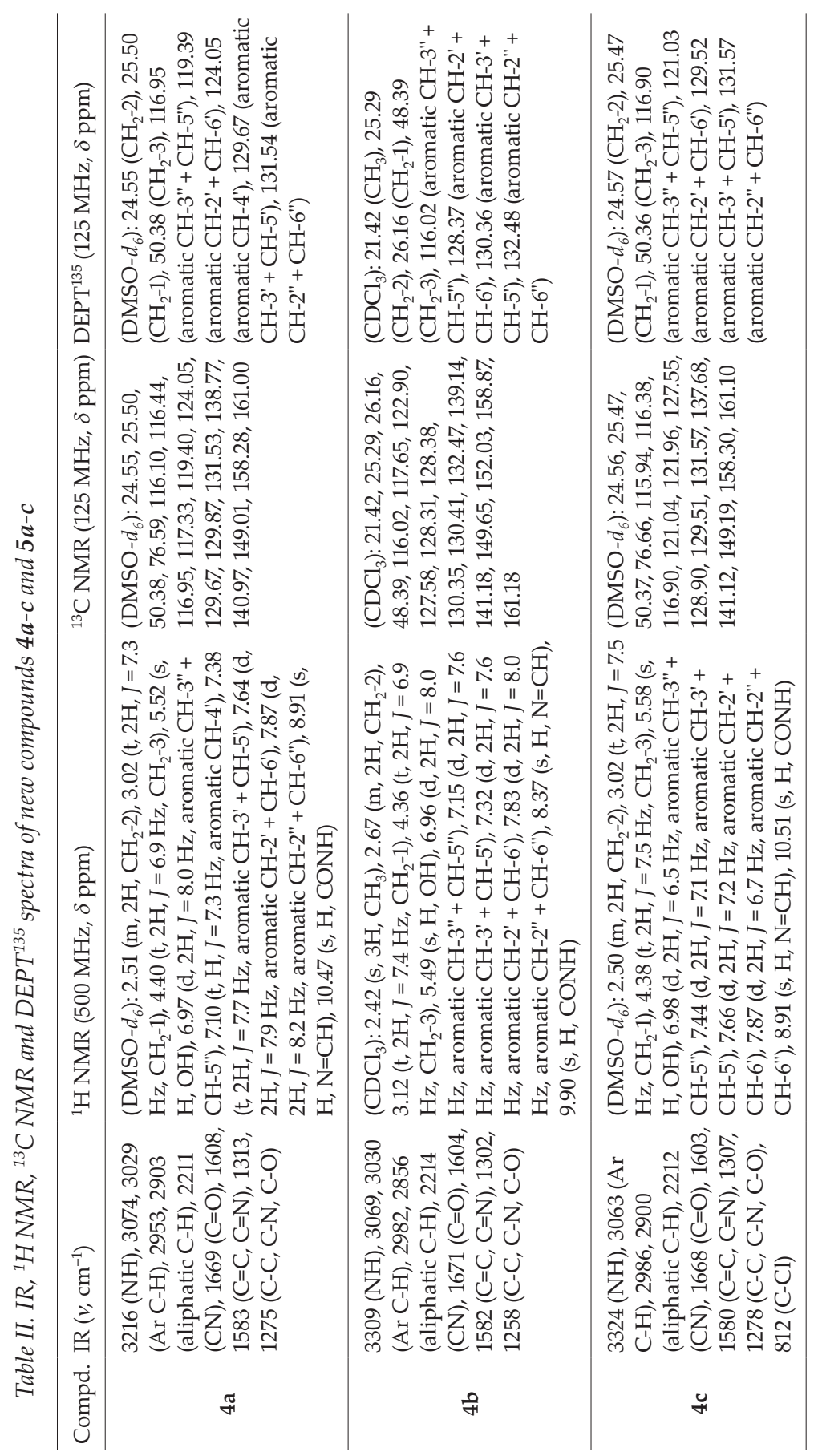




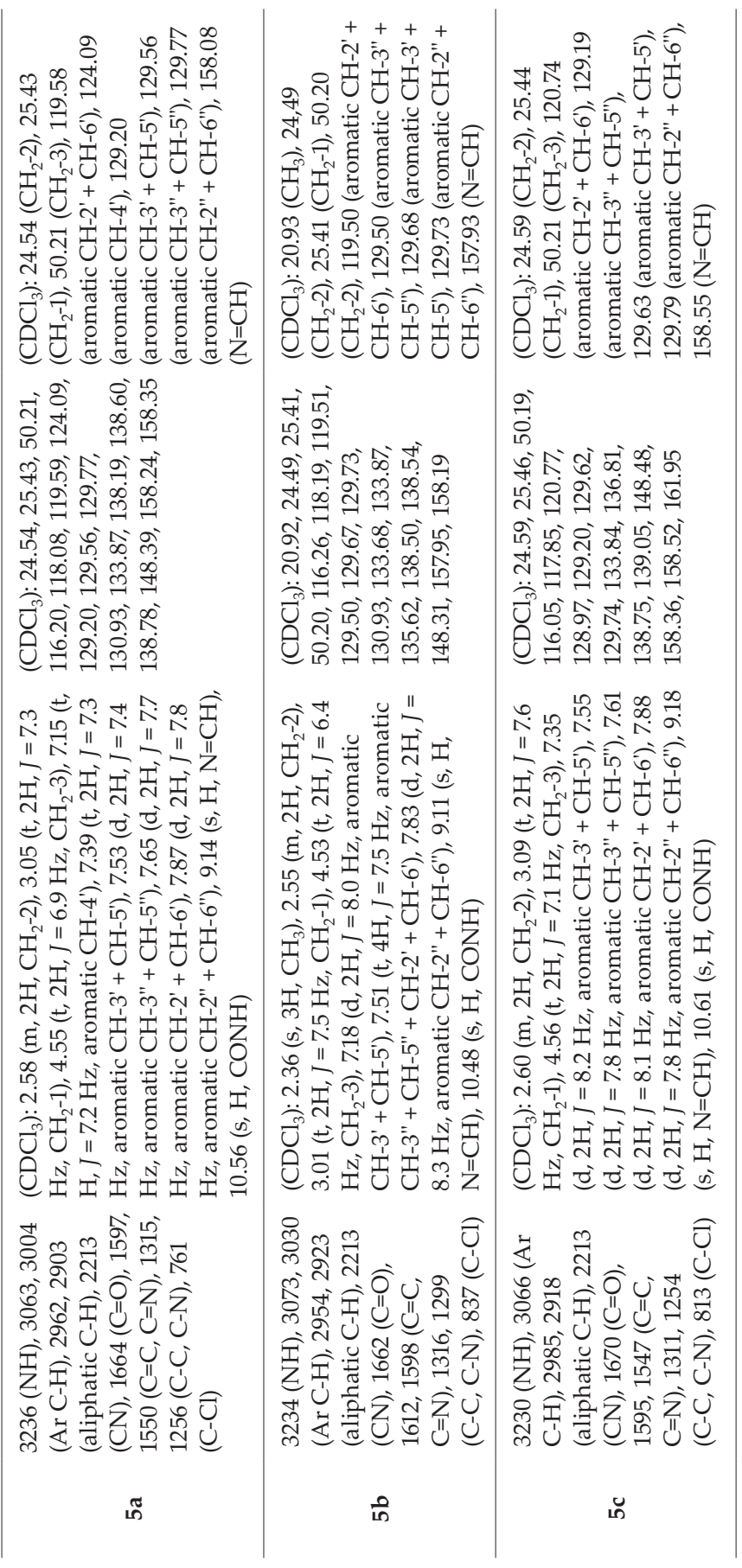




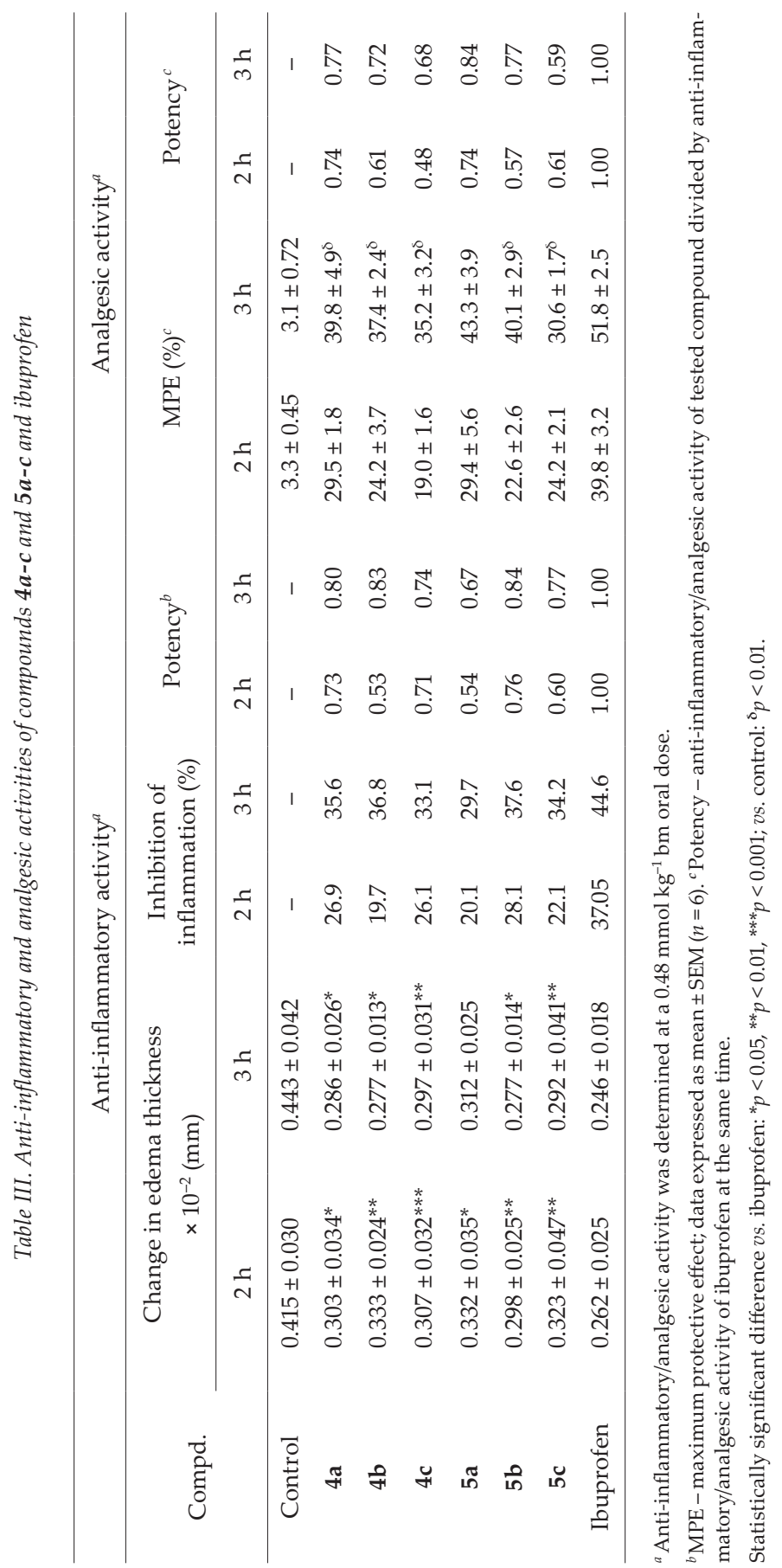


ibuprofen (100 mg kg-1 bm), and the test compounds (both $0.48 \mathrm{mmol} \mathrm{kg}^{-1} \mathrm{bm}$ ) were given orally. Experimental procedures were performed following a previous report (10). Analgesic effect of the tested compounds was calculated as the percentage of the maximal protective effect. Results are presented in Table III.

In vitro COX-1/2 inhibition assay. - All new compounds (4a-c and 5a-c) were tested for their inhibitory activity against both COX-1 (ovine) and COX-2 (human recombinant) enzymes. A COX inhibitor screening assay kit (Cayman Chemicals, USA) was used in the assay. The assay was done following the manufacturer's instructions and as mentioned before (24). The results were presented as \% inhibition at a $10 \mu \mathrm{mol} \mathrm{L}^{-1}$ concentration of the new compounds. Indomethacin and celecoxib were used as reference drugs. Results are presented in Table IV.

\section{Growth inhibition}

Cell cultures. - Human breast MCF-7, ovarian A2780 and colon HT29 cancer cell lines were obtained from the American Type Culture Collection (Manassas, VA, USA). All cells were cultured in Dulbecco's modified Eagle medium (DMEM) supplemented with $10 \%$ fetal bovine serum (FBS, Gibco, USA) in a humidified incubator containing $5 \% \mathrm{CO}_{2}$ at $37^{\circ} \mathrm{C}$.

Cytotoxic activity. - The MTT (3-[4,5-dimethylthiazole-2-yl]-2,5-diphenyltetrazolium bromide, Merck, Germany) assay was used to investigate the anticancer activity of the new compounds following a previous report (25). Cells were seeded for $24 \mathrm{~h}\left(3 \times 10^{3}\right)$ in 96-well flat-bottomed plates. Seeded cells were then treated with the test compounds or lapatinib $(n=6)$. DMSO vehicle $(0.1 \%, V / V)$ was used as a negative control. Cells were treated with the tested compounds in final drug concentrations of $0.00,0.05,0.50,5.00,25.00$ and 50.00 $\mu \mathrm{mol} \mathrm{L} \mathrm{L}^{-1}$. After $72 \mathrm{~h}, \mathrm{MTT}$ was added for $3 \mathrm{~h}$ at $37^{\circ} \mathrm{C}$. Reduced MTT was dissolved in DMSO (100 $\mu \mathrm{L}$ per well). Absorbance was measured using a microplate reader at $570 \mathrm{~nm}$ and the

Table IV. In vitro inhibition of COX-1/2 enzymes by compounds $4 \boldsymbol{a}-\boldsymbol{c}, \mathbf{5} \boldsymbol{a}-\mathrm{c}$ and reference drugs

\begin{tabular}{ccc}
\hline \multirow{2}{*}{ Compd. } & \multicolumn{2}{c}{ Inhibition $(\%)^{a}$} \\
\cline { 2 - 3 } & COX-1 & COX-2 \\
\hline $\mathbf{4 a}$ & 28 & 42 \\
$\mathbf{4 b}$ & 24 & 42 \\
$\mathbf{4} \mathbf{5}$ & 31 & 48 \\
$\mathbf{a}$ & 32 & 46 \\
$\mathbf{5 b}$ & 31 & 40 \\
$\mathbf{5} \mathbf{c}$ & 18 & 41 \\
Indomethacin & 72 & 63 \\
Celecoxib & 49 & 76 \\
\hline
\end{tabular}

${ }^{a}$ Inhibition of COX-1 (ovine) and COX-2 (human recombinant) at $10 \mu \mathrm{mol} \mathrm{L}-1$. 
Table V. $\mathrm{IC}_{50}$ values of compounds $4 \boldsymbol{a}-\mathrm{c}$ and $2 \boldsymbol{a}-\mathrm{c}$ against MCF-7, A2780 and HT29 cancer cell lines

\begin{tabular}{|c|c|c|c|c|c|c|}
\hline \multirow{2}{*}{ Compd. } & \multirow{2}{*}{$\mathrm{R}_{1}$} & \multirow{2}{*}{$\mathrm{R}_{2}$} & \multicolumn{4}{|c|}{$I C_{50}\left(\mu \mathrm{mol} \mathrm{L}{ }^{-1}\right)$} \\
\hline & & & MCF-7 & A2780 & HT29 & Average value \\
\hline $4 a$ & $\mathrm{H}$ & $\mathrm{OH}$ & $0.31 \pm 0.05$ & $2.56 \pm 0.29$ & $0.96 \pm 0.13$ & 1.28 \\
\hline $4 b$ & $\mathrm{CH}_{3}$ & $\mathrm{OH}$ & $0.76 \pm 0.60$ & $0.92 \pm 0.05$ & $0.30 \pm 0.16$ & 0.67 \\
\hline $4 c$ & $\mathrm{Cl}$ & $\mathrm{OH}$ & $0.08 \pm 0.01$ & $0.52 \pm 0.02$ & $3.79 \pm 1.39$ & 1.46 \\
\hline $5 a$ & $\mathrm{H}$ & $\mathrm{Cl}$ & $1.12 \pm 0.66$ & $0.78 \pm 0.30$ & $0.37 \pm 0.05$ & 0.76 \\
\hline $5 b$ & $\mathrm{CH}_{3}$ & $\mathrm{Cl}$ & $0.33 \pm 0.12$ & $0.44 \pm 0.01$ & $0.41 \pm 0.02$ & 0.40 \\
\hline $5 c$ & $\mathrm{Cl}$ & $\mathrm{Cl}$ & $1.77 \pm 0.29$ & $3.92 \pm 0.07$ & $0.72 \pm 0.07$ & 2.14 \\
\hline Lapatinib & - & - & $6.80 \pm 1.20$ & $10.40 \pm 0.80$ & $12.67 \pm 1.33$ & 9.96 \\
\hline
\end{tabular}

Results are mean \pm SD ( $n=6$ repetitive measurements, 3 independent experiments), after 72-h treatment with test compounds, lapatinib or $0.1 \%$ DMSO (control).

readings were corrected by subtracting the negative control readings. Experiments were repeated three times independently. Results are represented in Table V.

Annexin V PI/FITC apoptosis assay. - Annexin V Propidium iodide/fluorescein isothiocyanate (PI/FITC) was used to evaluate the ability of compound $\mathbf{5 b}$ to induce apoptotic changes in MCF-7 cells. Experimental procedures were done as previously reported (26). Three experiments were performed independently. Results are presented in Fig. 5.

\section{Statistics}

Anti-inflammatory and analgesic data were analyzed by One-way ANOVA followed by the Student-Newman-Keuls multiple comparison test.

\section{Computational studies}

Drug-likeness study. - Although a huge number of anticancer agents with potent activity in vitro have been reported in the last three decades, only a few have passed to clinical trials. This problem is mainly due to the ADME (absorption, distribution, metabolism and elimination) problems. In this work, the drug-likeness related parameters were deter- 
A. M. Gouda et al.: Pyrrolizine-5-carboxamides: Exploring the impact of various substituents on anti-inflammatory and anticancer activities, Acta Pharm. 68 (2018) 251-273.

Table VI. Molecular properties related to drug-likeness of compounds $4 a-c, 5 a-c$ and licofelone

\begin{tabular}{ccccccccccc}
\hline Compd. & $M_{\mathrm{r}}$ & $\mathrm{MV}^{a}$ & $\mathrm{MR}$ & $\mathrm{TPSA}$ & $\mathrm{Mlog} P$ & $\mathrm{RBs}$ & $\mathrm{H}_{\mathrm{A}}$ & $\mathrm{H}_{\mathrm{D}}$ & LVs & $\mathrm{DLS}^{a}$ \\
\hline $\mathbf{4 a}$ & 370.4 & 382.82 & 108 & 90.41 & 1.6 & 5 & 4 & 2 & 0 & 0.55 \\
$\mathbf{4 b}$ & 384.43 & 403.76 & 112.97 & 90.41 & 1.81 & 5 & 4 & 2 & 0 & 0.57 \\
$\mathbf{4 c}$ & 404.85 & 400.01 & 113.01 & 90.41 & 2.08 & 5 & 4 & 2 & 0 & 1.00 \\
$\mathbf{5 a}$ & 388.85 & 389.46 & 110.99 & 70.18 & 2.63 & 5 & 3 & 1 & 0 & 0.76 \\
$\mathbf{5 b}$ & 402.88 & 410.40 & 115.95 & 70.18 & 2.84 & 5 & 3 & 1 & 0 & 0.81 \\
$\mathbf{5 c}$ & 423.29 & 406.66 & 116 & 70.18 & 3.11 & 5 & 3 & 1 & 0 & 0.84 \\
Licofelone & 379.88 & 383.88 & 110.13 & 42.23 & 4.26 & 4 & 2 & 1 & $1^{b}$ & 0.58 \\
\hline
\end{tabular}

DLS - drug-likeness score, $\mathrm{H}_{\mathrm{A}}$ - hydrogen bond acceptors, $\mathrm{H}_{\mathrm{D}}$ - hydrogen bond donors, $\mathrm{LVs}$ - Lipinski violation, $M_{\mathrm{r}}$ - molecular mass, MV - molecular volume, TPSA - topological polar surface area, Mlog $P$ - Moriguchi's $\log P$, RBs - rotatable bonds

${ }^{a}$ Parameters calculated using Molsoft: http://molsoft.com/mprop/; other parameters calculated using SwissADME (http://www.swissadme.ch/).

${ }^{\mathrm{b}}$ There is one violation $(\mathrm{M} \log P>4.15)$.

mined for the new compounds according to Lipinski's "rule of five" (27). The predicted values of the physicochemical properties of the new compounds were calculated using the SwissADME webserver developed by the Swiss Institute of Bioinformatics (SIB, Switzerland, http://www.swissadme.ch/) (28). Results are represented in Table VI.

The molecular mass (MW), molar refractivity (MR), lipophilicity $(\mathrm{Mlog} P)$, number of hydrogen bond donors $\left(\mathrm{H}_{\mathrm{D}}\right)$, number of hydrogen bond acceptors $\left(\mathrm{H}_{\mathrm{A}}\right)$, Lipinski violations (27), number of rotatable bonds and topological polar surface area (TPSA) of the new compounds $4 \mathbf{a}-\mathbf{c}$ and $5 \mathbf{a}-\mathbf{c}$ and of licofelone were calculated. Chemical structures of the new compounds were sketched using the Marvin JS sketcher (version 16.4.18, 2016, www.chemaxon.com), converted to smiles by the JChem web service and processed through a series of actions when the calculation started upon clicking "RUN". The results were obtained as an Excel output file. The molecular volume and drug-likeness score (DLS) were calculated using the Molsoft webserver developed by Molsoft LLC (USA, http://molsoft.com/mprop/). The results are presented in Table VI.

Molecular docking study. - Docking study of all the new compounds was performed on COX enzymes. AutoDock 4.2 was used in the study and a Discovery Studio Visualizer (v16.1.0.15350) was used in visualization of the docking poses. Crystal structures of COX-1 (pdb code: 1EQG) (29) and COX-2 (pdb code: 1CX2) (30) were obtained from the protein data bank (http://www.rcsb.org/pdb). The protein structure was prepared by deleting water molecules and native ligands. Validation of the docking studies was done by re-docking the native ligands with their corresponding proteins. Binding modes and interactions of the native ligands with the key amino acids in the active site were identified and compared with the reported data. 
Preparation of the protein (COX-1, COX-2) pdbqt files. - Crystal structures of the proteins co-crystallized with the native ligands were obtained from the Protein Data Bank (http:// www.rcsb.org/pdb) as pdb files. COX-1 (pdb code: 1EQG) and COX-2 (pdb code: 1CX2) were obtained in X-ray resolution of 2.61 and $3.0 \AA$, resp. $(29,30)$. A discovery studio visualizer (DSV, v16.1.0.15350) was used to handle the protein structures. During preparation of the proteins, water molecules and bound ligands were removed to avoid interference with the study. The pdb files of the test compounds were prepared using Chem3D Ultra 8.0 followed by MOPAC energy minimization. The docking study was performed using AutoDock 4.2.

Preparation of ligand files. - Chemical structures of the new compounds were sketched using the ChemDraw Ultra 8.0 software. Chem3D Ultra 8.0 was used in the preparation of the ligand in the pdb format. Energies of the ligands were minimized using MOPAC with 100 iterations. The AutoDock Tool 1.5.6 was used to read the pdb files, add the hydrogens, compute Gasteiger charges, and to convert the pdb into the pdbqt format for the docking study. The docking scenario was done using flexible ligands while the rotatable bonds in the ligands were assigned using AutoDock tools (ADT) 1.5.6.

Preparation of affinity maps and running AutoGrid. - Preparation of the Grid parameter files by AutoDock was done using AutoGrid, which generated a map for each type of atom in the docking area. The 3D grids with the final size of $60 \times 60 \times 60 \AA$ with $0.375 \AA$ spacing were used in the study. The center of the grid for COX-1 was assigned at 26.643, 33.106 and 200.251 $\AA$, and for COX-2 at 23.947, 21.582 and $15.436 \AA$.

Preparation of the docking parameter file and running AutoDock. - The protein molecule and the ligand were selected to run AutoDock and perform docking calculations. The docking parameter file was set to the default values. In this study, we set the proteins as a rigid file while ligands were used as flexible molecules. Lamarckian genetic algorithm was set as the search parameter. After running AutoDock, the top ten conformations of the protein-ligand complex were clustered. Docking poses were scored and ranked in decreasing order of their binding free energy.

Analysis and visualization of the results. - AutoDock 4.2. was used in the analysis of the docking results, determination of the binding free energy $\left(\Delta G_{b}\right)$ and inhibition constants $\left(K_{\mathrm{i}}\right)$. Binding modes of the ligand and the type of ligand-protein interactions were vitalized using a discovery studio visualizer (v16.1.0.15350). The 2D/3D binding mode was visualized showing both hydrogen bonding and hydrophobic interactions. The docking results are presented in Table VII and Figs. 6 and 7.

\section{RESULTS AND DISCUSSION}

\section{Chemistry}

Preparations of 2-pyrrolidin-2-ylidene-malononitrile (1), 2-chloro-1N-[4-(un)substituted-phenyl)-acetamides (2a-c) and 6-amino-7-cyano- $N$-[4-(un)substituted-phenyl]-2,3-dihydro- $1 H$-pyrrolizine-5-carboxamides (3a-c) outlined in Scheme I were achieved following previous reports (19-21). 


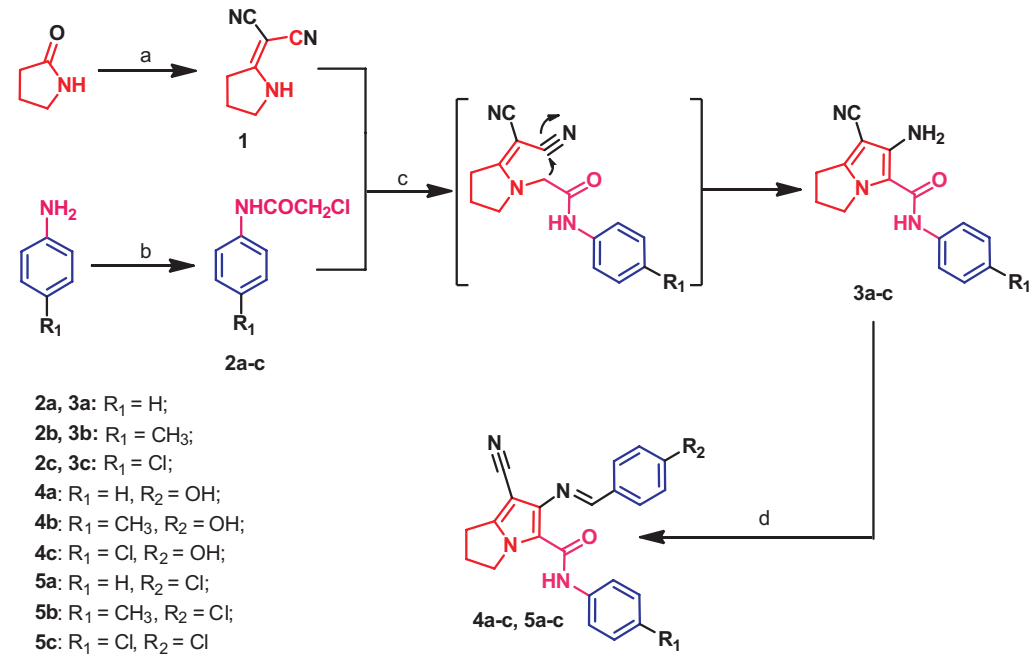

Reagents and reaction conditions: a) $\left(\mathrm{CH}_{3}\right)_{2} \mathrm{SO}_{4}$, benzene, malononitrile, b) $\mathrm{ClCH}_{2} \mathrm{COCl}$, glacial acetic acid, $\mathrm{CH}_{3} \mathrm{COONa}$, c) $\mathrm{K}_{2} \mathrm{CO}_{3}$, acetone, reflux, $24 \mathrm{~h}$, d) appropriate aldehyde (4-hydroxy/4-chloro-benzaldehyde), ethanol, acetic acid, reflux, $6 \mathrm{~h}$.

Scheme 1

Schiff bases 4a-c and 5a-c were obtained by the reaction of compounds 3a-c with a proper aldehyde (4-hydroxybenzaldehyde or 4-chlorobenzaldehyde) in ethanol (see Scheme 1). Structural characterization of new compounds $4 \mathbf{a}-\mathbf{c}$ and 5a-c was accomplished using IR, ${ }^{1} \mathrm{H}$ NMR, ${ }^{13} \mathrm{C}$ NMR and mass spectra, in addition to elemental analyses (Tables I and II).

IR spectra of the new compounds $4 \mathbf{a}-\mathbf{c}$ and $5 \mathbf{a}-\mathbf{c}$ revealed absorption bands in the range of $3216-3324 \mathrm{~cm}^{-1}$ indicating the $\mathrm{NH}$ of the amide groups, absorption bands in the range of 2211-2214 $\mathrm{cm}^{-1}$ assigned to the cyano groups and stretching bands in the range of $1662-1671 \mathrm{~cm}^{-1}$ attributed to the carbonyl groups.

${ }^{1} \mathrm{H}$ NMR spectra of compounds 4a-c revealed three signals in the range of $2.50-4.56 \mathrm{ppm}$ attributed to the aliphatic methylene groups of pyrrolizine nucleus. The ${ }^{1} \mathrm{H}$ NMR spectrum of compound $4 \mathrm{~b}$ revealed a singlet signal at $2.42 \mathrm{ppm}$ assigned to the methyl group. A singlet signal in the range of 5.49-5.58 ppm was due to the protons of hydroxyl (OH) groups in compounds 4a-c. Aromatic protons of compound $4 \mathbf{a}$ appeared as two triplets at 7.10 and $7.38 \mathrm{ppm}$, in addition to three doublets at 6.97, 7.64 and $7.87 \mathrm{ppm}$, while the aromatic protons in compounds $4 \mathrm{~b}$ and $4 \mathrm{c}$ appeared as four doublets in the range of 6.96-7.87 ppm. Two singlet signals were observed in the range of $8.37-10.51$ ppm indicating benzylidene and amide protons, respectively. Superimposition of aromatic and amide protons in compound $4 a$ and in the intermediate compound (6-amino-7-cyano- $\mathrm{N}$-phenyl-2,3-dihydro-1H-pyrrolizine-5-carboxamide) showed two new aromatic signals, in addition to a singlet signal of the benzylidene $(\mathrm{N}=\mathrm{CH})$ proton (Fig. 2).

The ${ }^{1} \mathrm{H}$ NMR spectrum of compound $5 \mathrm{~b}$ showed a singlet signal at $2.36 \mathrm{ppm}$ due to the methyl group. Moreover, the ${ }^{1} \mathrm{H}$ NMR spectrum of compound 5 a revealed three signals in the 


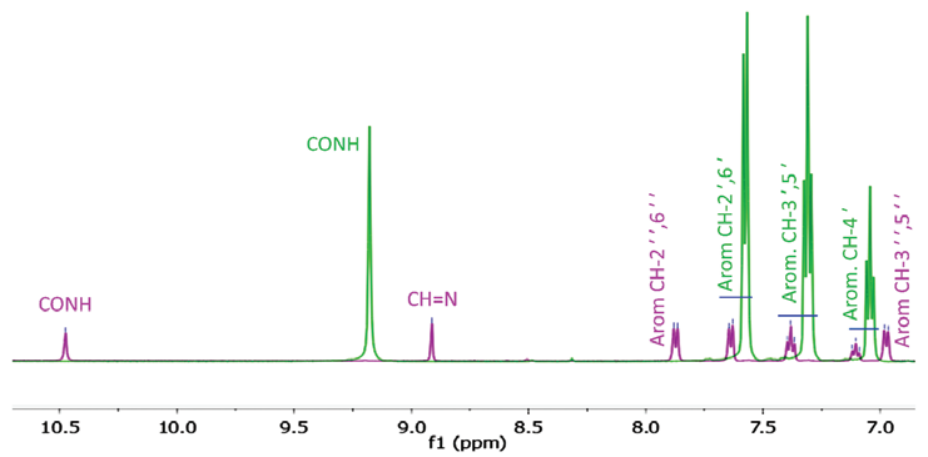

Fig. 2. Superimposition of the aromatic, benzylidene and amidic protons in compound $4 a$ (green) over the corresponding protons of compound $\mathbf{3 a}$ (pink).

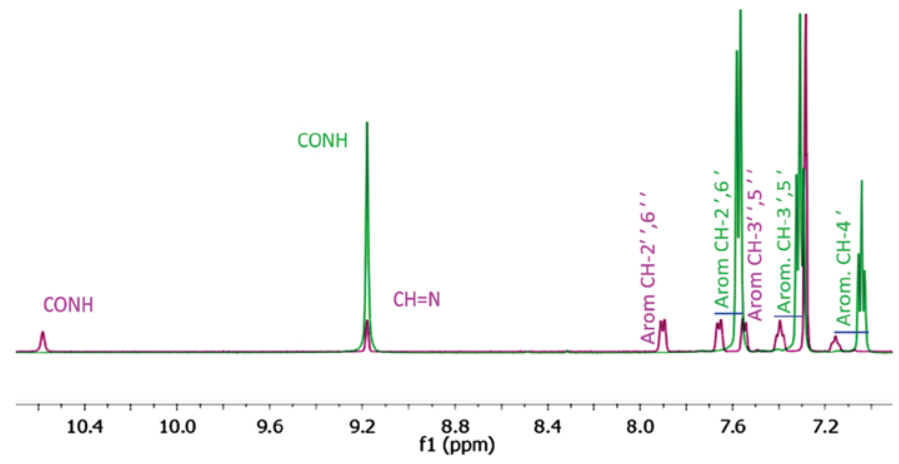

Fig. 3. Superimposition of the aromatic, benzylidene and amidic protons in compound 5 a (green) on the respective protons of compound $3 \mathbf{a}$ (pink).

range of 2.55-4.56 ppm attributed to the methylene groups of the pyrrolidine ring. Aromatic protons of compound 5 a appeared as two triplets at 7.15 and 7.39 ppm plus three doublets at $7.53,7.65$ and $7.87 \mathrm{ppm}$, while the aromatic protons in compounds $5 \mathbf{b}$ and $5 \mathbf{c}$ appeared as four doublets in the range of 7.17-7.88 ppm indicating para-substituted phenyl rings. Two singlet signals at 8.91 and $10.47 \mathrm{ppm}$ indicated benzylidene and amide protons, resp.

Superimposition of aromatic and amide protons in compound $5 \mathbf{a}$ and the preceding compound 3a showed two new aromatic signals, in addition to the benzylidene $(\mathrm{N}=\mathrm{CH})$ proton (Fig. 3).

On the other hand, the ${ }^{13} \mathrm{C}$ NMR spectra of compounds 4a-c and 5a-c revealed three signals in the range of $24.49-50.38$ ppm attributed to the three aliphatic carbons of the pyrrolizine nucleus, two signals at 21.42 and $20.92 \mathrm{ppm}$ attributed to the methyl $\left(\mathrm{CH}_{3}\right)$ groups in compounds $\mathbf{4 b}$ and $\mathbf{5 b}$, resp. In addition, two signals in the range of $157.95-161.95 \mathrm{ppm}$ were assigned to the benzylidene $(\mathrm{C}=\mathrm{NH})$ and carbonyl carbons in compounds $4 \mathrm{a}-\mathrm{c}$ and $5 a-c$. 


\section{Pharmacological screening}

In vivo anti-inflammatory activity. - Results of the anti-inflammatory activity are given as changes in edema thickness, inhibition of inflammation and relative potency compared to ibuprofen (Table III).

It was noticed that all new compounds showed moderate anti-inflammatory activity with relative potency in the range of 0.53-0.84 compared to ibuprofen. Ibuprofen and the new compounds (4a-c and $\mathbf{5 a - c})$ were significantly different from the control $(p=$ $0.001)$.

Compounds $\mathbf{4 a}$ and $\mathbf{5} \mathbf{a}$ with the unsubstituted phenyl ring displayed anti-inflammatory activity of 35.6 and $29.7 \%$, resp. In general, the methyl-substituted analogs ( $4 \mathbf{b}$ and $\mathbf{5 b}$ ) displayed higher anti-inflammatory activity than the other derivatives (Table III).

In vivo analgesic activity. - Results from Table III revealed that all new compounds have analgesic activity lower than ibuprofen. Compounds $4 a-c$ with the 4-hydroxy substituent were less active than their 4 -chloro analogs $5 \mathbf{a}-\mathbf{c}$. Compound $\mathbf{5 a}$ showed the highest analgesic activity after 3 hours (Table III).

In vitro COX-1/2 inhibitory activity. - New compounds 4 a-c and 5a-c displayed inhibitory activity for COX-1/2 enzymes with inhibition in the range of $18-32 \%$ for COX-1 and $41-48 \%$ for COX-2 at $10 \mu \mathrm{mol} \mathrm{L}^{-1}$. Compound $4 \mathrm{c}$ bearing 4-hydroxyphenyl was the most active COX-2 inhibitor while compound 5 a was the most active inhibitor of COX-1. All new compounds displayed inhibitory activity against COX-1 and COX-2 enzymes with inhibition lower than that of both the non-selective COX inhibitor (indomethacin) and the selective COX-2 inhibitor (celecoxib). All the inhibitions by the tested compounds were in the range of $18-48 \%$ at $10 \mathrm{mmol} \mathrm{L}^{-1}$, indicating that their $\mathrm{IC}_{50}$ values could be higher than 10 $\mathrm{mmol} \mathrm{L}^{-1}$ (Table IV).

\section{Anticancer activity}

In vitro MTT assay. - New compounds showed cytotoxic activity against the three cell lines with $I C_{50}$ values in the range of 0.08 to $3.92 \mu \mathrm{mol} \mathrm{L}^{-1}$, compared to lapatinib with $I C_{50}$ of 6.80-12.67 $\mu \mathrm{mol} \mathrm{L}^{-1}$ (Table V). The 4-hydroxy derivatives 4a-c displayed $I_{50}$ values in the range of $0.08-3.79 \mu \mathrm{mol} \mathrm{L}^{-1}$ while the 4 -chloro analogs $5 \mathrm{a}-\mathrm{c}$ were slightly less active $\left(I C_{50}=\right.$ 0.33-3.92 $\mu \mathrm{mol} \mathrm{L}^{-1}$ ) against the three cell lines. Compounds $4 \mathbf{c}, 4 \mathbf{b}$ and $5 \mathbf{b}$ were the most active against the MCF-7, A2780 and HT29 cancer cell lines.

\section{Structure activity relationship (SAR)}

Compound 4a displayed $I C_{50}$ values of $0.31,2.56$ and $0.96 \mu \mathrm{mol} \mathrm{L}^{-1}$ against MCF-7, A2780 and HT29 cells, resp. Substitution on ring A with the electron donating methyl group increased activity against the A2780 and HT29 cells, while the 4-chloro substitution increased activity against the MCF-7 and A2780 cancer cell lines. Moreover, replacement of 4-hydroxy in compound $4 \mathbf{a}$ with the chloro group (compound 5a) resulted in an increase in activity against the A2780 and HT29 cell lines (Fig. 4).

The anticancer activity of compounds $5 \mathbf{a}-\mathbf{c}$ was dependent on the type of substituent on ring $\mathrm{A}$. The 4 -methyl substituent in compound $5 \mathbf{b}$ increased the activity against both 


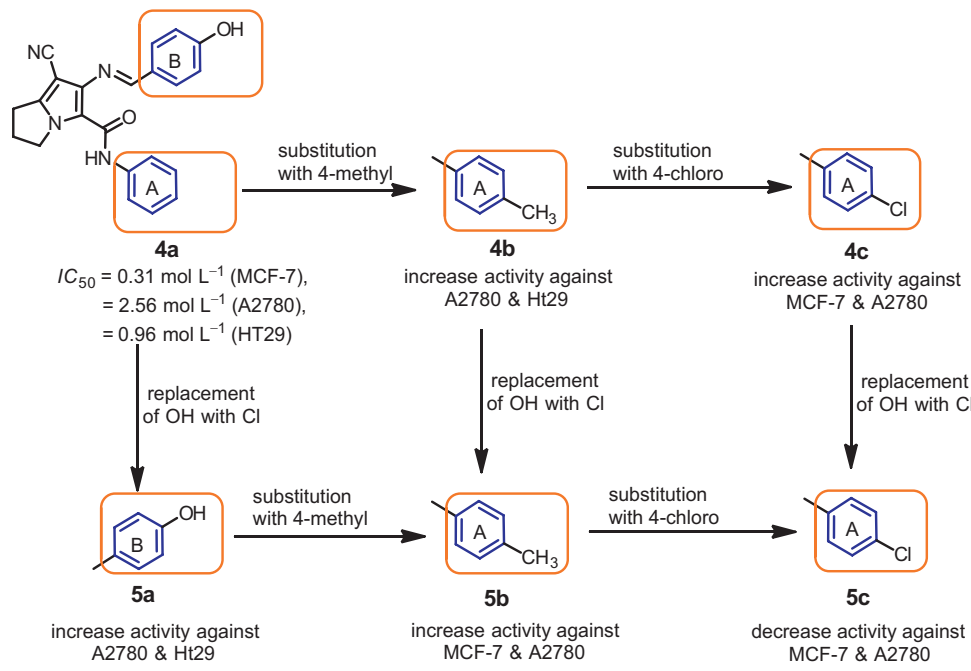

Fig. 4. SAR of the anticancer activity of the new compounds $4 \mathbf{a}-\mathbf{c}$ and $5 \mathrm{a}-\mathrm{c}$.

MCF-7 and A2780 cells, while the 4-chloro decreased the activity against the three cell lines. On the other hand, replacement of the 4-hydroxy group in compound $4 \mathrm{~b}$ with the chloro group resulted in an increase of anticancer activity against both MCF-7 and A2780 cells, while replacement of the 4-hydroxy group in compound 4c with the chloro group decreased the anticancer activity against both MCF-7 and A2780 cells.

In general, the electronic effect of various substituents on the anticancer activity varied with the cell line. Compound $4 \mathrm{c}$ with the electron withdrawing $\mathrm{Cl}$-group displayed higher activity against the MCF-7 and A2780 cell lines than compounds $4 \mathbf{a}$ and $4 \mathbf{b}$, while the methyl derivative $5 \mathrm{~b}$ was more active than compounds $4 \mathrm{a}$ and $4 \mathrm{c}$ against these two cell lines. Accordingly, substituents on rings A and B of opposite electronic effects enhanced the anticancer activity against the MCF-7 and A2780 cell lines (Fig. 4).

\section{Annexin V FITC/PI apoptosis assay}

Annexin V propidium iodide(PI)/fluorescein isothiocyanate (FITC) apoptosis assay was used to evaluate the ability of the most active compound ( $5 \mathbf{b})$ to induce apoptosis, following a previous report (26). The results are presented in Fig. 5. Compound 5b induced dose dependent early apoptosis C4 (early apoptosis): 10.6, 32.4, 33.6 and $41.7 \%$, resp., for 0 , 1,5 and $10 \mu \mathrm{mol} \mathrm{L}{ }^{-1}$. Only $0.1-0.2 \%$ necrosis (C1) was induced in the MCF-7 cell population by compound $5 \mathbf{b}$, following a 24 -hour treatment. Compound $\mathbf{5 b}$ caused at least four-fold increase in the early apoptotic events.

\section{Computational study}

Drug-likeness study. - The results revealed that the new compounds $4 \mathbf{a}-\mathbf{c}$ and $5 \mathbf{a}-\mathrm{c}$ have a molecular mass < 500, Moriguchi's lipophilicity $(\mathrm{Mlog} P)$ lower than 5, hydrogen bond 

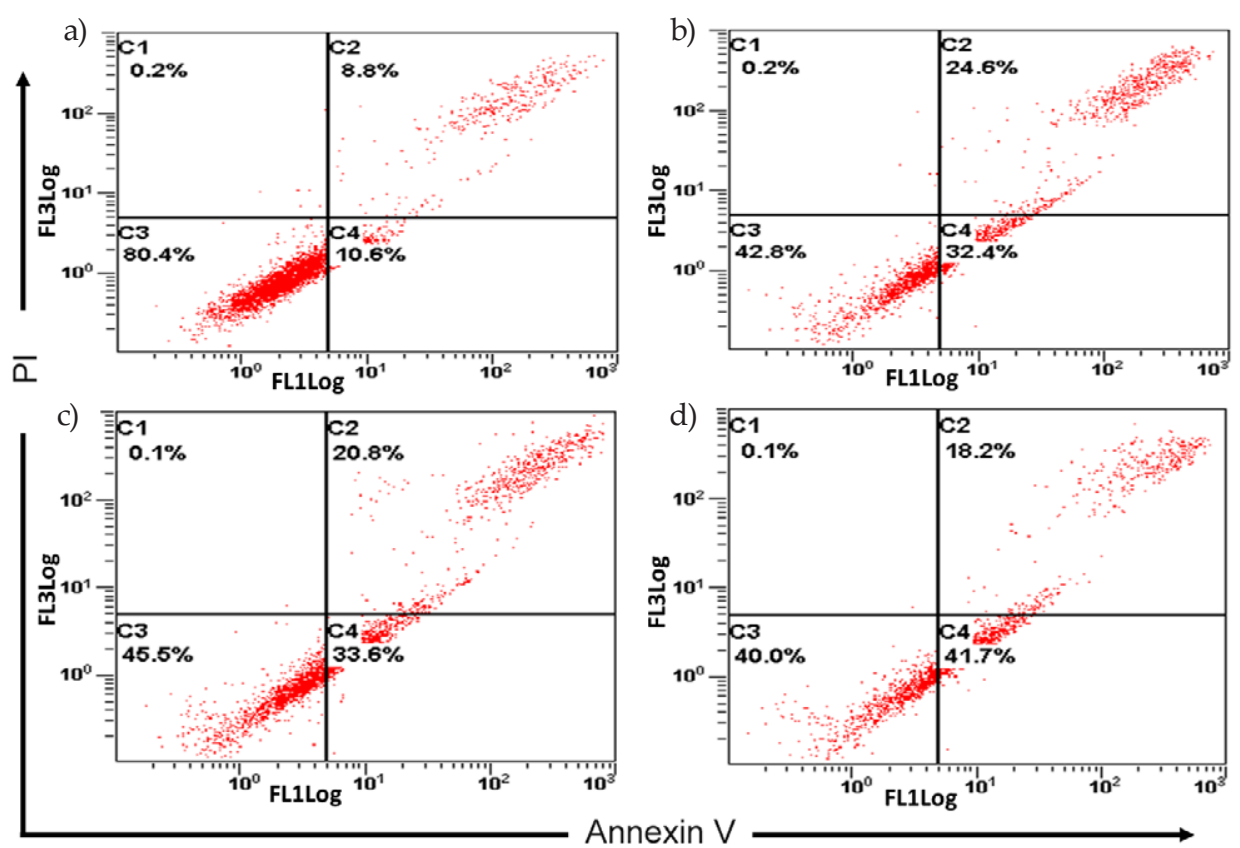

Fig. 5. Plots showing different phases of the staining of MCF-7 cells with annexin V FITC/PI, treated with compound $5 \mathbf{b}$, for $24 \mathrm{~h}$ : a) control, $0 \mu \mathrm{mol} \mathrm{L}^{-1}$, b) $1 \mu \mathrm{mol} \mathrm{L}^{-1}$, c) $5 \mu \mathrm{mol} \mathrm{L}^{-1}$, d) $10 \mu \mathrm{mol} \mathrm{L}^{-1}(n=3)$.

$\mathrm{x}$-axis: annexin $\mathrm{V}, \mathrm{y}$-axis: propidium iodide (PI)

C1: (necrosis-death, PI+/annexin V-); C2: (late apoptosis, PI+/ annexin V+); C3: (living cells, PI-/annexin V-); C4: (early apoptosis, PI-/annexin V+).

acceptor $\left(\mathrm{H}_{\mathrm{A}}\right)<10$, hydrogen bond donor $\left(\mathrm{H}_{\mathrm{D}}\right) \leq 5$, molar refractivity $(\mathrm{MR})$ between 40 and 130. Accordingly, all the new compounds have good drug-likeness scores in the range of 0.55-1.00 compared to 0.58 for licofelone. No violation of Lipinski's rule was observed for the new compounds, while licofelone showed one violation (see Table V).

\section{Docking study}

Due to the important role of COXs enzymes in inflammation, cell proliferation and apoptosis (4-7), a comparative docking study was performed to evaluate the binding modes and binding free energies of the new compounds into the active sites of COX-1/2.

Docking study into the active site of COX-1. - COX-1 (ovine) crystal structure complexed with ibuprofen (pdb code: 1EQG) (29) was obtained from the protein data bank (http://www. $\mathrm{rcsb} . \mathrm{org} / \mathrm{pdb} / \mathrm{home} /$ home.do). Validation of docking results was done by re-docking the native ligand (ibuprofen) into the active site of COX-1. A discovery studio visualizer (DSV) was used in visualization of the docking results. Docking results are presented in Table VII.

Results of the docking study revealed the ability of new compounds $4 \mathbf{a}-\mathbf{c}$ and $5 \mathbf{a}-\mathrm{c}$ to bind ARG120, TYR355, MET522 and SER530 amino acids in the active site of COX-1 with binding 
A. M. Gouda et al.: Pyrrolizine-5-carboxamides: Exploring the impact of various substituents on anti-inflammatory and anticancer activities, Acta Pharm. 68 (2018) 251-273.

Table VII. Results of the docking of compounds $4 a-c$ and $5 a-c$ into COX-1 in comparison with the native co-crystallized ligands ${ }^{a}$

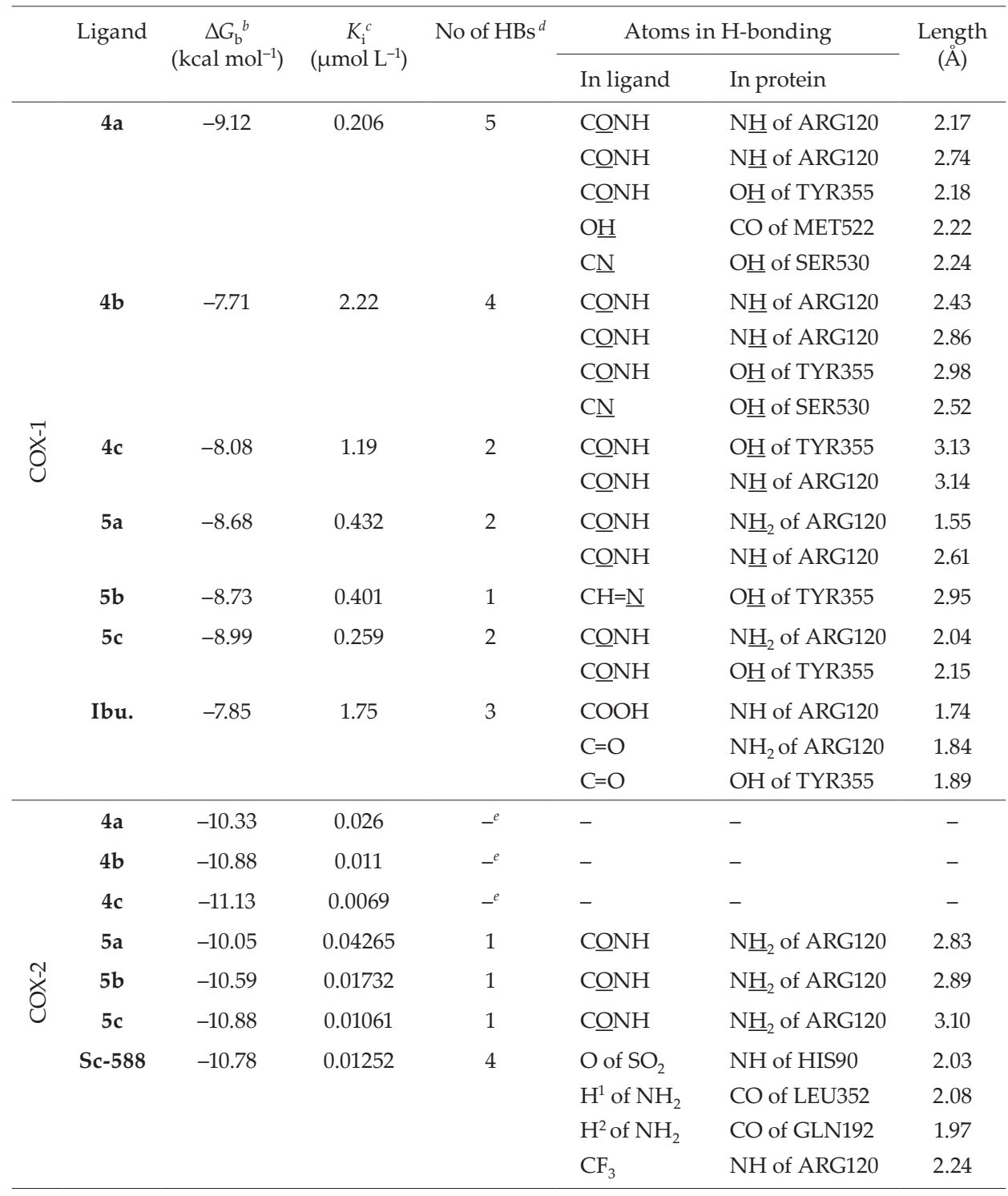

${ }^{\mathrm{a}}$ COX-1 (pdb: 1eqg) (ref. 29) and COX-2 (pdb: 1cx2) (ref. 30).

${ }^{\mathrm{b}}$ Binding free energy.

c Inhibition constant.

${ }^{\mathrm{d}} \mathrm{HBs}$ - hydrogen bonds.

e No hydrogen bond detected. 

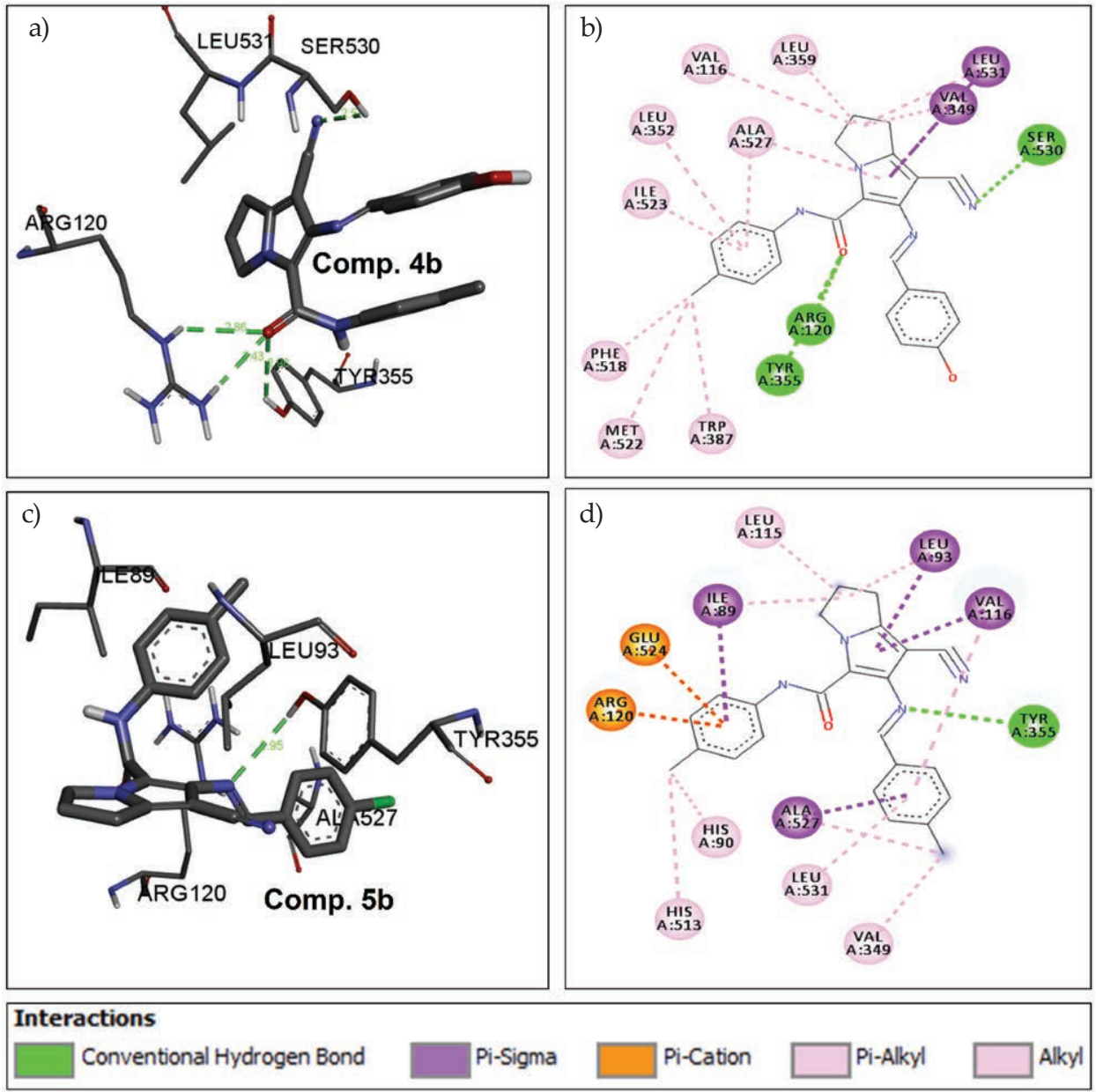

Fig. 6. a) 3D docking mode of compound $4 \mathbf{b}$ into COX-1 (pdb code: 1EQG) showing four hydrogen bonds with ARG120, TYR355 and SER530 amino acids, b) 2D docking mode of compound $\mathbf{4 b}$ into COX-1 showing four hydrogen bonds, twelve hydrophobic interactions of the pi-sigma, alkyl and pi-alkyl types, c) 3D docking mode of compound $5 \mathbf{b}$ into COX-1 (pdb code: 1EQG) showing one hydrogen bond with TYR355, d) 2D docking mode of compound $5 \mathbf{b}$ into COX-1 showing one hydrogen bond and fifteen hydrophobic interactions of the pi-cation, pi-sigma, alkyl and pi-alkyl types.

free energy in the range of -7.71 to $-9.12 \mathrm{kcal} \mathrm{mol}^{-1}$. Except for compound $4 \mathbf{b}$, all the new compounds showed binding affinity higher than ibuprofen $\left(\Delta G_{\mathrm{b}}=-7.85 \mathrm{kcal} \mathrm{mol}^{-1}\right)$. In addition, all the new compounds formed 1-5 hydrogen bonds with the amino acids in COX-1 (Table VII and Fig. 6).

Docking into the active site of COX-2. - New compounds were also docked into the active site of COX-2 using AutoDock 4.2. The crystal structure of COX-2 (pdb code: 1CX2) (30) was 

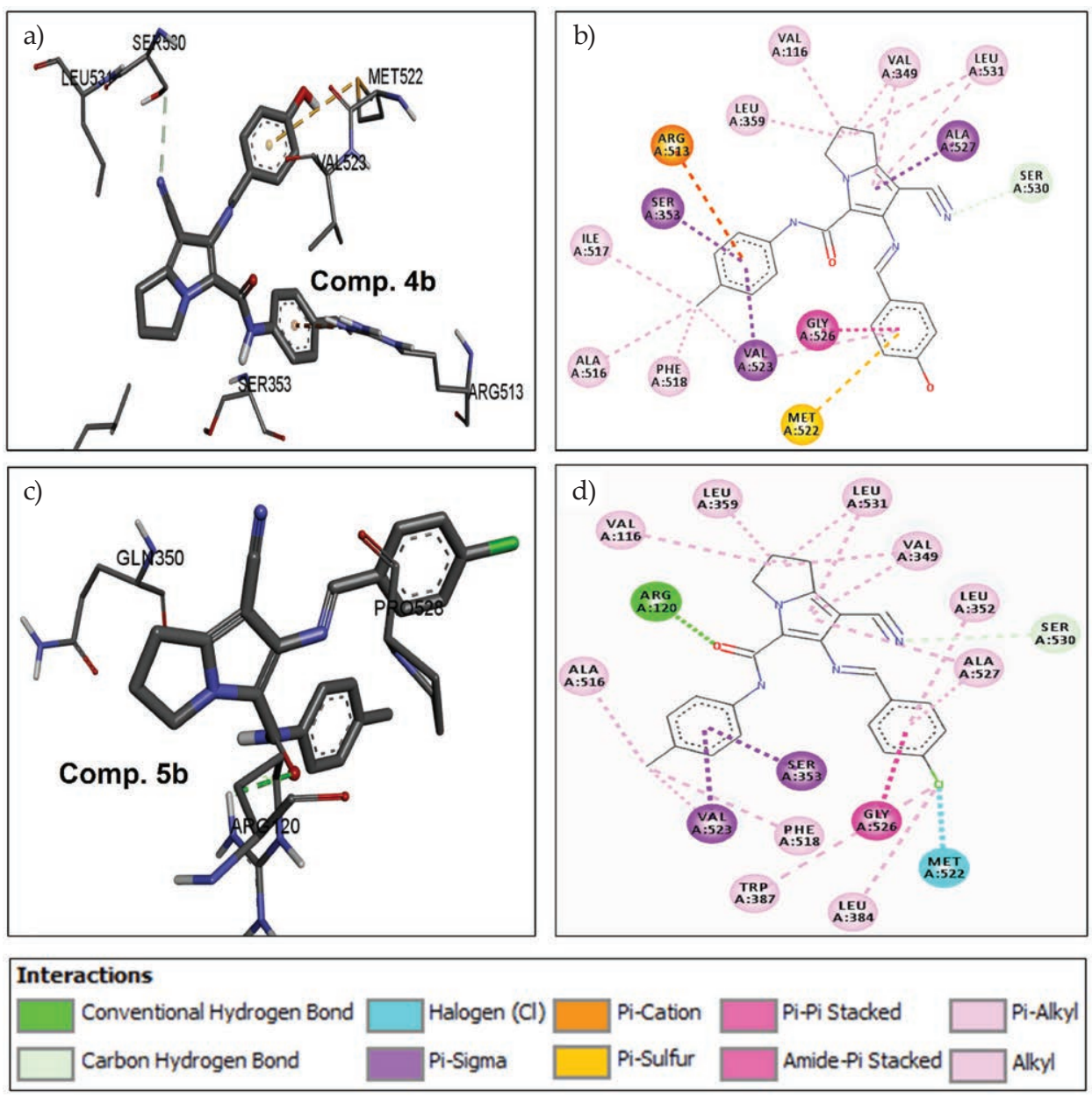

Fig. 7. a) 3D docking mode of compound $4 \mathbf{b}$ into COX-2 (pdb code: 1CX2), b) 2D docking mode of compound $4 \mathbf{b}$ into COX-2 showing eighteen hydrophobic interactions of the halogen $(\mathrm{Cl})$, pi-cation, pi-sulfur, pi-sigma, amide-pi stacked, alkyl and pi-alkyl types, c) 3D docking mode of compound $5 \mathbf{b}$ into COX-2 (pdb code: 1CX2) showing one hydrogen bond with ARG120, d) 2D docking mode of compound $\mathbf{5 b}$ into COX-2 showing one hydrogen bond, nineteen hydrophobic interactions of the carbon-hydrogen, halogen (Cl), pi-sigma, amide-pi stacked, alkyl and pi-alkyl types.

obtained from the protein data bank (http://www.rcsb.org/pdb/home/home.do). Validation of docking results was done through a re-docking scenario of the native ligand (SC-558) into the active site of the COX-2 enzyme. New compounds displayed binding affinities comparable to or slightly higher than the native ligand SC-558 (Table VII). Hydrophobic interaction was the main type of interaction between the new compounds and amino acids in the active site of the enzyme. Although compounds 5a-c showed only one hydrogen bonding with ARG120 in COX-2, their high binding affinities to COX-2 were mainly due to 
the formation of multiple hydrophobic interactions (Fig. 7). To sum up, compounds $4 \mathrm{c}$ and $5 \mathrm{c}$ with the 4-chloro substitution on ring A displayed higher binding affinity to COX-2 than their methyl (4b and $\mathbf{5 b}$ ) and unsubstituted analogs (4a and $5 \mathbf{a})$.

\section{CONCLUSIONS}

A novel series of pyrrolizine-5-carboxamides derivatives $4 \mathbf{a}-\mathbf{c}$ and $5 \mathbf{a}-\mathbf{c}$ was prepared and evaluated for their anti-inflammatory, analgesic and anticancer activities. (EZ)-7-cyano-6-((4-hydroxybenzylidene)amino)- $N$-( $p$-tolyl)-2,3-dihydro- $1 H$-pyrrolizine-5-carboxamide (4b) and (EZ)-6-((4-chlorobenzylidene)-amino)-7-cyano- $N$-(p-tolyl)-2,3-dihydro- $1 H$-pyrrolizine-5-carbox-amide $(5 \mathbf{b})$ bearing the electron donating methyl group showed the highest anti-inflammatory activity 3 hours after induction of inflammation, while (EZ)-7-cyano6-((4-hydroxybenzylidene)amino)- $N$-phenyl-2,3-dihydro-1H-pyrrolizine-5-carboxamide (4a) and (EZ)-6-((4-chlorobenzylidene)amino)-7-cyano- $N$-phenyl-2,3-dihydro-1H-pyrrolizine5 -carboxamide (5a) were the most active analgesic agents.

Cytotoxicity of the new compounds was evaluated against the MCF-7, A2780 and HT29 cancer cell lines where the results revealed high anticancer activity. Substituents with opposite electronic effects on the two phenyl rings enhanced the anticancer activity against the MCF-7 and A2780 cell lines. (EZ)-N-(4-chlorophenyl)-7-cyano-6-((4-hydroxybenzylidene)amino)-2,3-dihydro- $1 H$-pyrrolizine-5-carboxamide (4c) displayed the highest anticancer activity against the MCF-7 and A2780 cell lines with $I C_{50}$ values of 0.08 and $0.52 \mu \mathrm{mol} \mathrm{L}^{-1}$, resp. COX inhibition was suggested as the possible mechanism of action of the anti-inflammatory activity of the new compounds. Results of the COX-1/2 inhibition assay showed appreciable inhibitory activity with higher inhibitory activity of COX-2. Although compound 4c with the highest inhibition of COX-2 displayed the highest anticancer activity against the MCF-7 and A2780 cell lines, it was the least active against COX-2 producing HT29 cells. In addition, compound $\mathbf{5 b}$ which displayed the lowest inhibition of COX-2 was the most active against the three cancer cell lines. These findings suggest that targets other than COX enzymes mediate the anticancer activity of these compounds. Annexin V PI/FITC apoptosis assay revealed the ability of compound $\mathbf{5 b}$ to induce dose-dependent early apoptosis with $0.1-0.2 \%$ necrosis in MCF-7 cells.

The drug-likeness study showed promising bioactivity scores for the new compounds. The docking study of the new compounds into COX-1/2 revealed high binding affinities for COX-2. Taken together, this study has confirmed the significant impact of different substituents on the biological activity of pyrrolizine-5-carboxamides, which could help in further optimization to discover good leads for the treatment of cancer and inflammation.

Acknowledgements. - The authors thank the Deanship of Scientific Research at the Umm AlQura University for their continuous support. This work was supported financially by the Deanship of Scientific Research of the Umm Al-Qura University, Makkah, Kingdom of Saudi Arabia, to Dr. Ahmed Mahmoud Gouda Said (Grant Code: 15-MED-3-1-0059).

Supplementary data are available upon request.

\section{REFERENCES}

1. E. R. Rayburn, S. J. Ezell and R. Zhang, Anti-inflammatory agents for cancer therapy, Mol. Cell. Pharmacol. 1 (2009) 29-43; https://doi.org/10.4255/mcpharmacol.09.05 
2. M. J. Thun, S. J. Henley and C. Patrono, Nonsteroidal anti-inflammatory drugs as anticancer agents: mechanistic, pharmacologic, and clinical issues, J. Natl. Cancer Inst. 94 (2002) 252-266; https://doi.org/10.1093/jnci/94.4.252

3. S. R. Pedada, N. S. Yarla, P. J. Tambade, B. L. Dhananjaya, A. Bishayee, K. M. Arunasree, G. H. Philip, G. Dharmapuri, G. Aliev, S. Putta and G. Rangaiah, Synthesis of new secretory phospholipase A2-inhibitory indole containing isoxazole derivatives as anti-inflammatory and anticancer agents, Eur. J. Med. Chem. 112 (2016) 289-297; https://doi.org/10.1016/j.ejmech.2016.02.025

4. C. Sobolewski, C. Cerella, M. Dicato, L. Ghibelli and M. Diederich, The role of cyclooxygenase-2 in cell proliferation and cell death in human malignancies, Int. J. Cell Biol. 2010 (2010) 1-21; https:// doi.org/10.1155/2010/215158

5. C. S. Williams, M. Mann and R. N. DuBois, The role of cyclooxygenases in inflammation, cancer, and development, Oncogene 18 (1999) 7908-7916; https://doi.org/10.1038/sj.onc.1203286

6. C. Ruegg, J. Zaric and R. Stupp, Non-steroidal anti-inflammatory drugs and COX-2 inhibitors as anti-cancer therapeutics: hypes, hopes and reality, Ann. Med. 35 (2003) 476-487; https://doi. org/10.1080/07853890310017053

7. A. T. Koki and J. L. Masferrer, Celecoxib: a specific COX-2 inhibitor with anticancer properties, Cancer Control 9 (2002) 28-35; https://doi.org/10.1177/107327480200902S04

8. A. M. Gouda and A. H. Abdelazeem, An integrated overview on pyrrolizines as potential antiinflammatory, analgesic and antipyretic agents, Eur. J. Med. Chem. 114 (2016) 257-292; https://doi. org/10.1016/j.ejmech.2016.01.055

9. A. M. Gouda, A. H. Abdelazeem, H. A. Omar, A. N. Abdalla, M. A. S. Abourehab and H. I. Ali, Pyrrolizines: design, synthesis, anticancer evaluation and investigation of the potential mechanism of action, Bioorg. Med. Chem. 25 (2017) 5637-5651; https://doi.org/10.1016/j.bmc.2017.08.039 (in press)

10. A. M. Gouda, H. I. Ali, W. H. Almalki, M. A. Azim, M. A. S. Abourehab and A. H. Abdelazeem, Design, synthesis, and biological evaluation of some novel pyrrolizine derivatives as COX inhibitors with anti-inflammatory/analgesic activities and low ulcerogenic liability, Molecules 21 (2016) 1-21; https://doi.org/10.3390/molecules21020201

11. J.-P. Raynauld, J. Martel-Pelletier, P. Bias, S. Laufer, B. Haraoui, D. Choquette, A. D. Beaulieu, F. Abram, M. Dorais, E. Vignon and J.-P. Pelletier, Protective effects of licofelone, a 5-lipoxygenase and cyclo-oxygenase inhibitor, versus naproxen on cartilage loss in knee osteoarthritis: a first multicentre clinical trial using quantitative MRI, Ann. Rheum. Dis. 68 (2009) 938-947; https://doi. org/10.1136/ard.2008.088732

12. W. Liu, J. Zhou, K. Bensdorf, H. Zhang, H. Liu, Y. Wang, H. Qian, Y. Zhang, A. Wellner, G. Rubner, W. Huang, C. Guo and R. Gust, Investigations on cytotoxicity and anti-inflammatory potency of licofelone derivatives, Eur. J. Med. Chem. 46 (2011) 907-913; https://doi.org/10.1016/j.ejmech.2011.01.002

13. S. Tavolari, M. Bonafe, M. Marini, C. Ferreri, G. Bartolini, E. Brighenti, S. Manara, V. Tomasi, S. Laufer and T. Guarnieri, Licofelone, a dual COX/5-LOX inhibitor, induces apoptosis in HCA-7 colon cancer cells through the mitochondrial pathway independently from its ability to affect the arachidonic acid cascade, Carcinogenesis 29 (2008) 371-380; https://doi.org/10.1093/carcin/bgm265

14. S. Tavolari, A. Munarini, G. Storci, S. Laufer, P. Chieco and T. Guarnieri, The decrease of cell membrane fluidity by the non-steroidal anti-inflammatory drug Licofelone inhibits epidermal growth factor receptor signalling and triggers apoptosis in HCA-7 colon cancer cells, Cancer Lett. 321 (2012) 187-194; https://doi.org/10.1016/j.canlet.2012.02.003

15. V. Lisowski, C. Enguehard, J. Lancelot, D. Caignard, S. Lambel, S. Leonce, A. Pierre, G. Atassi, P. Renard and S. Rault, Design, synthesis and antiproliferative activity of tripentones: a new series of antitubulin agents, Bioorg. Med. Chem. Lett. 11 (2001) 2205-2208; https://doi.org/10.1016/S0960$894 X(01) 00403-6$ 
16. V. Lisowski, S. Leonce, L. Kraus-Berthier, J. Sopkova-de Oliveira Santos, A. Pierre, G. Atassi, D.-H. Caignard, P. Renard and S. Rault, Design, synthesis, and evaluation of novel thienopyrrolizinones as antitubulin agents, J. Med. Chem. 47 (2004) 1448-1464; https://doi.org/10.1021/jm030961z

17. C. Rochais, T. Cresteil, V. Perri, M. Jouanne, A. Lesnard, S. Rault and P. Dallemagne, MR22388, a novel anti-cancer agent with a strong FLT-3 ITD kinase affinity, Cancer Lett. 331 (2013) 92-98; https://doi.org/10.1016/j.canlet.2012.12.017

18. A. M. Gouda, A. H. Abdelazeem, E.-S. A. Arafa and K. R. A. Abdellatif, Design, synthesis and pharmacological evaluation of novel pyrrolizine derivatives as potential anticancer agents, Bioorg. Chem. 53 (2014) 1-7; https://doi.org/10.1016/j.bioorg.2014.01.001

19. A. Etienne and Y. Correia, Derivatives of 2-pyrrolidone, Bull. Soc. Chem. 10 (1969) 3704-3712.

20. W. A. Jacobs and M. Heidelberger, The ferrous sulfate and ammonia method for the reduction of nitro to amino compounds, J. Am. Chem. Soc. 39 (1917) 1435-1439; https://doi.org/10.1021/ ja02252a017

21. M. Y. Ebeid, S. M. El-Moghazy, M. M. Hanna, F. A. Romeih and F. F. Barsoum, Synthesis and antiHIV activity of some 6,7-dihydro-5H-pyrrolizine-3-carboxamide, 5,6,7,8-tetrahydroindolizine-3-carboxamide, 1-thioxo-1,2,3,5,6,7,8,9,10,11-decahydro-pyrimido-[1,6-a]azonine-4-carbonitrile and 6-thioxo-1,2,5,6,8,9,10,11,12,13,14,14a-dodecahydro-pyrimido[4',5:4,5]pyrimido-[1,6-a]azonine-1-one derivatives, Bull. Fac. Pharm. Cairo Univ. 35 (1997) 171-183.

22. C. A. Winter, E. A. Risley and G. W. Nuss, Carrageenan induced edema in hind paw of the rats as an assay for anti-inflammatory drugs, Proc. Soc. Exp. Biol. Med. 111 (1962) 544-547; https://doi.org/10.3181/00379727-111-27849

23. A. Mollica, R. Costante, A. Stefanucci, F. Pinnen, G. Lucente, S. Fidanza and S. Pieretti, Novel cyclic biphalin analogue with improved antinociceptive properties, J. Pept. Sci. 19 (2013) 233-239; https://pubs.acs.org/doi/10.1021/ml500241n

24. N. Handler, W. Jaeger, H. Puschacher, K. Leisser and T. Erker, Synthesis of novel curcumin analogues and their evaluation as selective cyclooxygenase-1 (COX-1) inhibitors, Chem. Pharm. Bull. (Tokyo) 55 (2007) 64-71; https://doi.org/10.1248/cpb.55.64

25. E.-S. A. Arafa, A. H. Abdelazeem, H. H. Arab and H. A. Omar, OSU-CG5, a novel energy restriction mimetic agent, targets human colorectal cancer cells in vitro, Acta Pharmacol. Sin. 35 (2014) 394-400; https://doi.org/10.1038/aps.2013.183

26. I. Vermes, C. Haanen, H. Steffens-Nakken and C. Reutellingsperger, A novel assay for apoptosis. Flow cytometric detection of phosphatidylserine expression on early apoptotic cells using fluorescein labelled Annexin V, J. Immunol. Methods 184 (1995) 39-51; https://doi.org/10.1016/00221759(95)00072-I

27. C. A. Lipinski, F. Lombardo, B. W. Dominy and P. J. Feeney, Experimental and computational approaches to estimate solubility and permeability in drug discovery and development settings, Adv. Drug Deliv.Rev. 23 (1997) 3-25; https://doi.org/10.1016/S0169-409X(96)00423-1

28. A. Daina, O. Michielin and V. Zoete, SwissADME: a free web tool to evaluate pharmacokinetics, drug-likeness and medicinal chemistry friendliness of small molecules, Sci. Rep. 7 (2017) Article ID 42717; https://doi.org/10.1038/srep42717

29. B. S. Selinsky, K. Gupta, C. T. Sharkey and P. J. Loll, Structural analysis of NSAID binding by prostaglandin $\mathrm{H} 2$ synthase: time-dependent and time-independent inhibitors elicit identical enzyme conformations, Biochemistry 40 (2001) 5172-5180; https://doi.org/10.1021/bi010045s

30. R. G. Kurumbail, A. M. Stevens, J. K. Gierse, J. J. McDonald, R. A. Stegeman, J. Y. Pak, D. Gildehaus, J. M. Miyashiro, T. D. Penning, K. Seibert, P. C. Isakson and W. C. Stallings, Structural basis for selective inhibition of cyclooxygenase-2 by anti-inflammatory agents, Nature 384 (1996) 644-648; https://doi.org/10.1038/384644a0 